\title{
COMPETITION OR COOPERATION IN A HUB AND SPOKE-SHIPPING NETWORK: THE CASE OF THE NORTH ADRIATIC CONTAINER TERMINALS
}

\author{
Danijela Tuljak-Suban \\ Faculty of Maritime Studies and Transport, University of Ljubljana, Slovenia \\ Submitted 13 March 2014; resubmitted 13 June 2014; accepted 11 December 2014; \\ published online 16 January 2017
}

\begin{abstract}
This article examines the problem of the competition or cooperation of the container terminals in the North Adriatic hub and spoke system with respect to the leadership position of the ship owners, which defines the flow of containers. The problem is defined as a two-stage game where the shipping companies act as leaders and the container terminals are the followers. The stages of the game are defined as a multi-objective optimization problem on a graph. The proposed simulations and the results obtained could be a first step in defining a sustainable method of collaboration in the hub and spoke system between the ports and the ship owners. The purpose of the article is also to present a systematic examination of a hub and spoke port network based on a competition-cooperation model. The model could also be used by the shipping companies or container terminals to find an optimal strategy in the game and validate their business decisions.
\end{abstract}

Keywords: maritime transport; container terminals; hub-and-spoke network design; game theory; multi-objective optimization; graph optimization.

\section{Introduction}

The transport of goods by containers is growing continuously. The economic global crisis has created a situation whereby ship operators as well as ports have to meet their needs more effectively in order to fall in line with global trends in maritime transportation. It is the goal of the North Adriatic container port system to compete with the major terminal ports of Northern Europe. In this, their geographical location certainly increases their competitiveness but not enough to guarantee economic stability. In the past, these ports acted separately and were located in three different countries under different jurisdictions. The consequences of this situation are still visible as even up till today, they have not yet implemented an effective common policy. The hub and spoke system is the most commonly used system worldwide since ships of the greatest capacity deliver to hubs that are connected to small ports through feeder services.

Before the inclusion of Croatia and Slovenia into the European Union, the ports of the North Adriatic developed as separate entities and generally competed with each other. The ports that make up this system are the port of Rijeka in Croatia, the port of Koper in
Slovenia and the ports of Trieste and Venice in Italy. In March 2010 these ports, along with the canal port of Ravenna, established the North Adriatic Ports Association (NAPA) with the aim of developing a common platform that could compete with the ports of Northern Europe, especially in the area of container transhipment (NAPA 2013; MDSTL 2012). In November 2012, the port of Ravenna left the association, since the volume of container transhipping and the port characteristics are not similar to the other ports.

Due to their geographical location, these ports play the role of spoke ports connected to a hub port located in the Mediterranean and of providing easier access to the largest container ships coming from the Far East.

Such analysis methods are frequently used to develop new solutions that render container transhipment more effective.

The Table 1 is an overview of recent articles that have dealt with this issue. Articles are grouped in chronological order in four categories with respect to their field of investigation. Firstly, articles that explain theoretical aspects of game theory and bi-level optimizations are presented. Secondly, works where methods 
of designing shipping networks are explained. Thirdly, the applications of Game theory in port competition analysis are presented and, finally, the economic aspect is presented.

In this article, the relationships between the ports' container terminal incomes and the incurred costs of the ship operators in these areas are analysed. Analytically, using game theory and the linear optimization models approach, the level of appropriate collaboration in this case can be detected.

Although geographically close, the North Adriatic container terminals are very different from each other with respect to the depth of the sea, the hinterland and organization systems. The Western port of Venice is more strongly connected to the local hinterland than the Eastern ports of Trieste, Koper and Rijeka, which serve Central and Eastern Europe, the Balkans, Austria and Southern Germany.

The total container throughput in 2012 in the ports of the NAPA system was 1.5 million TEU, which was ten times lower than the container throughput in Rotterdam
(11.8 million TEU). The terminal capacity of Rijeka is 0.2 million TEU with a utilisation capacity of about $80 \%$; the terminal capacity of Trieste is 0.6 million TEU and the utilisation capacity is about $50 \%$; the terminal capacity of Venice is 0.7 million TEU and the utilisation capacity is 55\% and the terminal capacity of Koper is 0.7 million TEU with a utilisation capacity of $70 \%$ (NAPA 2013; MDSTL 2012).

The intra NAPA ports' container traffic is an important part of the total container throughput of those parts: approximately $20 \%$ of the traffic in the port of Venice takes place inside the NAPA system, about $20 \%$ of the arrival and $7 \%$ of the departure traffic in the port of Trieste takes place inside the NAPA system, $40 \%$ of the traffic in the port of Koper takes place inside the NAPA system and approximately $15 \%$ of the traffic in the port of Rijeka takes place inside the NAPA system (NAPA 2013).

In the article, a model, which could be used to analyse the North Adriatic hub and spoke system will be proposed. This is vital in order to improve the role of

Table 1. Container terminal competition and ship-owner costs minimization methods (review of articles)

\begin{tabular}{|c|c|c|c|}
\hline Field of investigation & Reference article & Objective of investigation & $\begin{array}{c}\text { Methods of } \\
\text { investigation }\end{array}$ \\
\hline \multirow{2}{*}{ Theoretical bases } & Turocy, Stengel (2003) & Game theory & $\begin{array}{l}\text { Overview of the } \\
\text { theoretical bases }\end{array}$ \\
\hline & Colson et al. (2007) & Overview of bi-level optimization & $\begin{array}{l}\text { Overview of the } \\
\text { theoretical bases }\end{array}$ \\
\hline \multirow{2}{*}{$\begin{array}{l}\text { Shipping network } \\
\text { design }\end{array}$} & Imai et al. (2009) & Multi-port vs. hub-and-spoke port network & $\begin{array}{l}\text { Network optimization } \\
\text { methods }\end{array}$ \\
\hline & Wang, Wang (2011) & $\begin{array}{l}\text { Global shipping network design in a hub-and-spoke } \\
\text { system }\end{array}$ & $\begin{array}{l}\text { Network optimization } \\
\text { methods }\end{array}$ \\
\hline \multirow{8}{*}{$\begin{array}{l}\text { Game theory } \\
\text { application in port } \\
\text { competition analysis }\end{array}$} & Saeed, Larsen (2010b) & Container terminal concessions in Pakistan & Game theory \\
\hline & Saeed, Larsen (2010a) & $\begin{array}{l}\text { Cooperative game among container terminals } \\
\text { of a port }\end{array}$ & Two-stage game \\
\hline & Meng, Wang (2011) & $\begin{array}{l}\text { Equilibrium constraints model for a hub-and-spoke } \\
\text { network design problem with multiple stakeholders } \\
\text { and multi-type containers }\end{array}$ & $\begin{array}{l}\text { Hybrid genetic } \\
\text { algorithm }\end{array}$ \\
\hline & Chen et al. (2012) & $\begin{array}{l}\text { Scheduling model for mixed cross-operation in } \\
\text { container terminals }\end{array}$ & $\begin{array}{l}\text { Bi-level genetic } \\
\text { algorithm }\end{array}$ \\
\hline & Song, Dong (2012) & $\begin{array}{l}\text { Cargo routing and empty container repositioning } \\
\text { in a shipping network with multiple service routes }\end{array}$ & $\begin{array}{l}\text { Two-stage integer } \\
\text { programming }\end{array}$ \\
\hline & Asgari et al. (2013) & $\begin{array}{l}\text { Hub ports and shipping companies competition } \\
\text { and cooperation }\end{array}$ & $\begin{array}{l}\text { Two-stage game, } \\
\text { branch and bound } \\
\text { method of solution }\end{array}$ \\
\hline & Ishii et al. (2013) & $\begin{array}{l}\text { Analysis of port competition with game theory } \\
\text { method }\end{array}$ & Non-cooperative game \\
\hline & Saeed, Larsen (2013) & Bertrand model in case of two ports & Game theory \\
\hline \multirow{4}{*}{ Economic aspect } & Chang et al. (2008) & $\begin{array}{l}\text { Port selection factors by shipping lines: Different } \\
\text { perspectives between trunk liners and feeder service } \\
\text { providers }\end{array}$ & Economic methods \\
\hline & Liu, Medda (2009) & $\begin{array}{l}\text { Container terminals efficiency analysis in } \\
\text { Mediterranean Sea }\end{array}$ & Economic methods \\
\hline & $\begin{array}{l}\text { Panayides, Wiedmer } \\
(2011)\end{array}$ & $\begin{array}{l}\text { Strategic alliances in container liner shipping } \\
\text { caused by the economic crisis in the years between } \\
2008 \text { and } 2010\end{array}$ & $\begin{array}{l}\text { Types of alliances } \\
\text { review }\end{array}$ \\
\hline & Acciaro (2013) & Review of port pricing methods & Literature review \\
\hline
\end{tabular}


the ports in the system and to define a model of effective collaboration that allows the NAPA system to compete with the large ports of North Europe. Chang et al. (2008) have demonstrated that feeder services are less sensitive to port costs than shipping lines, so a variation in the Terminal Handling Costs (THC) could be a good method of increasing the competitiveness inside the system and outside with respect to the other ports of the North of Europe.

The proposed approach could be used to improve the existing alliances by finding a strategy, which would be able to validate their business decisions and increase their role inside the European port system.

\section{Game Theory Approach}

As previously explained, the behaviour of the various elements (spoke ports, shipping companies) involved in the North Adriatic hub and spoke system can be described as a set of strategic moves such as those made by the players in a game (Turocy, Stengel 2003).

In game theory (Rasmusen 2006) a game is a mathematical model of strategic behaviours. Commonly, a game involves many players who must make decisions at every decision point. In this way, each player defines his own strategy. The main purpose of game theory is, on the basis of those elements, to deduce an equilibrium strategy.

Games can be divided into cooperative (coalitional) and non-cooperative (competitive) games. In non-cooperative games the optimal strategy is generally defined by the Nash equilibrium. Sometimes games could be defined as hierarchical models where some players have a privileged role.

In maritime container transport, ports follow the requirements of shipping operators and try to increase their own container traffic. Small container ports of the Northern Adriatic are no exception, but their economic and geographic position raises a question: competition or cooperation?

To explain this situation, this article will use a bilevel game model with a leader and followers known as the Stackelberg Game (Saeed, Larsen 2010a). In this game, players compete with each other. The leader first makes his moves and then the followers react optimally (Dempe 2002; Asgari et al. 2013).

The levels of the game are:

- shipping operators as leaders, formulated as a Vehicle Routing Problem with Pickup and Delivery (VRPPD) (with one ship operator (leader) and one main hub port connected to the system (Toth, Vigo 2014);

- spoke ports as followers - formulated as a multi-objective optimization model (Colson et al. 2007).

\subsection{Shipping Operators as Leaders Optimization Part}

Ports are defined as a set of nodes $V(G)$ composed of three subsets: the main hub port, ports where containers are unloaded from ships that come from the hub port and ports where containers need to be taken towards the hub (or other) port in the system.

Since in a port containers could be loaded and unloaded on a ship, to determine a good strategy for feeder service on graph $G$, it is necessary to define a new graph $G_{T}$ where the set of nodes $N$ will be composed of two parts:

- takeover nodes: $P=\{1, \ldots, n\}$ are nodes where containers are loaded;

- delivery nodes: $D=\{n+1, \ldots, 2 n\}$ are nodes where containers are unloaded.

Nodes that denote contemporary takeover and delivery in the graph $G$, are considered twice in the graph $G_{T}$.

The connection between nodes from the set $P$ and those from the set $D$ in the graph $G_{T}$ is: each node $i \in$ $P$ is connected with node $n+i \in D$, because from node $i, d_{i}$ containers are transported to node $n+i$; therefore we define $l_{i}=d_{i}$ and $l_{n+i}=-d_{i}$, where $d_{i}$ are parameters obtained on the basis of the shipping companies market analysis.

The set $\kappa$ includes the minimum number of ships that can effectively supply the system's ports. The request that each voyage begins and ends at a hub port determines the upgrade of the graph $G_{T}$ into the operative graph $G_{S T}$, defined as graph product $G_{S T}=G_{T} *\{0\}$.

In this way, we can arrange for each ship $k \in \kappa$ a set $N_{k}=P_{k} \cup D_{k}$ of ports that it services. Sets $N_{k}, P_{k}$ and $D_{k}$ are subsets of sets $N, P$ and $D$. Thus, we can arrange for any ship $k \in \kappa$ a graph $G_{S T k}=\left(V_{k}, E_{k}\right)$, where $V_{k}=$ $N_{k} \cup\{0\}$ and $E_{k} \subseteq V_{k} \times V_{k}$.

For the ship operator, the optimization problem which minimizes the navigation and handling costs can be formulated as:

$$
\min \left\{\sum_{k \in K} \sum_{e_{i j} \in E_{k}} c_{i j k} x_{i j k}+\sum_{k \in K} \sum_{e_{i j} \in E_{k}} x_{i j k}\left|l_{i}\right| T H C_{i}\right\}
$$

submitted to the next conditions:

- condition 1: each port is serviced exactly once by the same ship:

$$
\begin{aligned}
& \sum_{k \in K} \sum_{j \in N_{k} \cup\{0\}} x_{i j k}=1, \forall i \in P_{k} ; \\
& \sum_{j \in N_{k}} x_{i j k}-\sum_{j \in N_{k}} x_{j, n+i, k}=0, \forall k \in \kappa, i \in P_{k} .
\end{aligned}
$$

- condition 2: every voyage of any ship starts and finishes at the hub port, denoted by 0 :

$$
\begin{aligned}
& \sum_{j \in P_{k} \cup\{0\}} x_{0 j k}=1, \forall k \in \kappa ; \\
& \sum_{i \in N_{k} \cup\{0\}} x_{i j k}-\sum_{i \in N_{k} \cup\{0\}} x_{j i k}=0, \forall k \in \kappa, j \in N_{k} ; \\
& \sum_{i \in D_{k} \cup\{0\}} x_{i 0 k}=1, \forall k \in \kappa .
\end{aligned}
$$

- condition 3: definition of the relations between the capacity of ship $k$ and the activity in neighbouring ports $i$ and $j \cdot \gamma_{i j}$ and $\gamma_{j i}$ are respectively 
the collaboration indices of the port $i$ respect to the port $j$ and vice versa, those values are connected with port capacity utilization and infrastructure:

$$
\begin{aligned}
& x_{i j k}\left(\gamma_{i j} L_{i k}+l_{j}-\gamma_{j i} L_{j k}\right)=0, \forall k \in \kappa, e_{i j} \in E_{k} ; \\
& 0 \leq \gamma_{i j}+\gamma_{j i} \leq 2, \forall e_{i j} \in E_{k} ; \\
& l_{i} \leq L_{i k} \leq C_{k}, \forall k \in \kappa, i \in P_{k} ; \\
& 0 \leq L_{n+i, k} \leq C_{k}-l_{i}, \forall k \in \kappa, n+i \in D_{k} .
\end{aligned}
$$

- condition 4: definition of the initial values and characteristics of the variables:

$$
L_{0, k}=0, \forall k \in \kappa \text {. }
$$

Variables and parameters used in the basic problem formulation are:

- $x_{i j k}$ are binary variables with a value of 1 when the ship $k$ uses connection $e_{i j} \in E_{k}$; otherwise the value is 0 ;

- $L_{i k}$ are variables that express the number of containers on the ship $k$ after landing in the port (node) $i \in V_{k}$, those values are related to the local and global container transhipment and demand;

$-C_{k}$ is the capacity [TEU] of the ship $k \in \kappa$;

- $c_{i j k}$ are the navigation costs of ship $k$ between ports $i$ and $j$.

- $T H C_{i}$ are variables which express the average handling cost $[€]$ per container at each port $i$. $T_{H C} \in[\underline{T H C}, \overline{T H C}]$, where $\underline{T H C}$ is the lower bound of the handling cost in this hub and spoke system and $\overline{T H C}$ is the upper bound of the handling cost in this hub and spoke system.

The basic solution gives the optimal route in the operative graph $G_{S T k}$, so it is necessary to map the solution into the basic graph $G_{k}$. Conditions (Eqs (7)-10)) assure that the shipped containers in graph $G_{S T K}$ correspond to the capacity of the ship, but the overlapping of paths in the minor $G_{k}$ causes conditions (Eqs (7)-10)) not to be fulfilled in the minor $G_{k}$.

On a defined path, let $j^{*} \in V\left(G_{k}\right)$ be the first node where the above mentioned conditions are not satisfied - the node $j^{*}$ is the ending of the connection $e^{*}{ }^{*}{ }^{*}$ $\in E\left(G_{k}\right)$. The ship's capacity is not enough to load all containers in port $j^{*}$. The priorities of the ship operator are to load the ship with as many containers as possible. If all the containers cannot be loaded, the empty ones are left at the terminal. Therefore $x^{*}{ }^{*}{ }^{*}{ }^{*} k=1$ and $\left(L^{*}{ }^{*} k+l^{*}{ }^{*}+w^{*} j^{*}-L_{j^{*} k}^{*}\right) \neq 0$. Therefore, the free capacity of the ship after leaving node $i^{*}$ is $C_{k}-L^{*}{ }^{*}{ }^{*} k$ and in the next node $j^{*}$ on the ship $l^{*} j^{*}$ containers have to be loaded and unloaded $w^{*}{ }^{*}$ containers $\left(w_{j_{*}^{*}}^{*}=l_{n+\tilde{i}=j^{*}}\right.$ for a proper index $\tilde{i})$, but $l^{*}{ }^{*} \geq C_{k}-L_{i^{*} k}^{*}+w^{j^{*}} *$ :

- if $l_{j^{*}}^{*}=\lambda_{j^{*}}^{j^{*}}+\lambda_{j^{*}}^{2}$, where $\lambda_{j^{*}}^{1}$ is the number of empty containers that is necessary to load onto the ship and $\lambda^{2}$ is the number of full containers that are loaded onto the ship, therefore the following applies:

$$
\begin{aligned}
& L_{j^{*} k}^{*}=\sup _{\Delta \lambda_{j^{*}}^{1} \leq \lambda_{j^{*}}^{1}}\left\{\Delta \lambda_{j^{*}}^{1}+\lambda_{j^{*}}^{2}\right\}+L_{i^{*} k}^{*}+w^{*}{ }_{j^{*}} \leq C_{k} ; \\
& - \text { if } l^{*}{ }_{j^{*}}=\lambda_{j^{*}}^{1} \text { then the following applies: } \\
& L^{*}{ }_{j^{*} k}=\sup _{\Delta \lambda^{1} \leq \lambda^{1}}\left\{\Delta \lambda_{j^{*}}^{1}\right\}+L_{i^{*} k}^{*}+w^{*}{ }_{j^{*}} \leq C_{k} ; \\
& \text { - if } l^{*}{ }_{j^{*}}=\lambda_{j^{*}}^{2} \text { then the following applies: } \\
& L^{*}{ }_{j^{*} k}=\sup _{\Delta \lambda_{j^{*}}^{1} \leq \lambda_{j^{*}}^{1}}\left\{\Delta \lambda_{j^{*}}^{2}\right\}+L_{i^{*} k}^{*}+w^{*}{ }_{j^{*}} \leq C_{k} .
\end{aligned}
$$

In case (Eq. (14)), it is reasonable to use a bigger ship because the capacity of the ship does not satisfy the needs of the ship owner for the transport of full containers. The procedure is repeated until all the nodes are analysed on the path, cycle in graph $G_{k}$.

\subsection{Spoke Ports as Followers Optimization Part}

The spoke port competition is formulated as a multiobjective optimization problem defined on the links and nodes of the graph $G$. The problem could be formulated in three ways:

1) Perfect competition between spoke ports. In this case the spoke ports individually solve the optimization problem:

$\max \left\{\sum_{k \in K} \sum_{e_{i j} \in E\left(G_{k}\right)} T H C_{i} x_{i j k}\left|l_{i}\right|\right\}$

subject to:

$T H C_{i} \in[\underline{T H C}, \overline{T H C}], \forall i \in V(G), i \neq 0$.

In this way, each spoke port tries to produce an optimal response by changing the terminal handling charges $T H C_{i}$, to the shipping company's dicta (Colson et al. 2007). At this stage of the game, the spoke port optimum is defined by the Nash equilibrium.

In this case, the previously described bi-level game is an example of the Stackelberg leader followers game (Nie 2011). The two levels of the game are connecting through common variables $x_{i j k}$ and $T H C_{i}$. The solution of the game is obtained by the branch and bound technique and the reduction of the bi-level game to a single level game by replacing condition (Eq. (15)) with the Karush-Kuhn-Tucker condition (Chong, Zak 2013).

2) Perfect cooperation between spoke ports. In this case for each pair of spoke ports $i$ and $j$ the collaboration indices $\gamma_{i j}$ and $\gamma_{j i}$ are equal to 1 . Ports collaborate to solve the optimization problem:

$\max \left\{\sum_{\substack{i \in V(G) \\ i \neq 0}} \sum_{\substack{k \in K \\ e_{i j} \in E\left(G_{k}\right)}} T H C_{i} x_{i j k}\left|l_{i}\right| \omega_{i}\right\}$

subject to: 


$$
\sum_{\substack{i \in V(G) \\ i \neq 0}} \omega_{i}=1,
$$

$\omega_{i}$ are relevance indices that express the importance of each spoke port in the hub and spoke system.

Reduction of the bi-level game to a single level game is the same as in the case of perfect competition with the exception of Eqs (15-16) which are replaced by Eqs (17-18).

3) Cooperation among spoke ports and shipping operators. In this case it is necessary to define a common objective function that takes into account the requirements of the leader (shipping operator) and of the followers (spoke ports). As it is necessary to introduce a multi-objective function, each player is represented by a component of the function (Marler, Arora 2004). Cooperation is expressed by the introduction of a pounderated Euclidian distance between the components of the objective function and the optimal values of objective functions $\mathrm{OPT}_{1}$ (Eq. (1)) and $\mathrm{OPT}_{2 i}$ (Eq. (17)), $i \in V(G)$ :

$\min \left(\sqrt{a_{0}-\omega_{1} a_{1}-\ldots-\omega_{V(G)} a_{V(G)}}\right)$,

where:

$a_{0}=\left(\frac{\sum_{k \in K} \sum_{e_{i j} \in E_{k}} c_{i j k} x_{i j k}+\sum_{k \in K} \sum_{e_{i j} \in E_{k}} x_{i j k}\left|l_{i}\right| T H C_{i}-O P T_{1}}{O P T_{1}}\right)^{2}$

$a_{1}=\left(\frac{\sum_{k \in K} \sum_{e_{i j} \in E_{k}} T H C_{i} x_{i j k}\left|l_{i}\right|-O P T_{21}}{O P T_{21}}\right)^{2} ;$

$a_{V(G)}=\left(\frac{\sum_{k \in K} \sum_{e_{i j} \in E_{k}} T H C_{i} x_{i j k}\left|l_{i}\right|-O P T_{2 V(G)}}{O P T_{V(G)}}\right)^{2}$.

The relevance indices $\omega_{i}$ express the importance of each port and are defined on the basis of the characteristics of the spoke ports and the requirements of the shipping operators.

\section{Numerical Example}

The implementation of the proposed model requires the availability of data, much of which is not in the public domain. For this reason some possible scenarios will be proposed: the case of competition and of cooperation between the spoke ports against a possible situation of the hegemony of the ship operator.

Gioia Tauro is a big container terminal in the Mediterranean that is often used as a hub port connected to the spoke ports of the North Adriatic. The characteristics of the container terminal are: $3145 \mathrm{~m}$ berth, $15.5 \mathrm{~m}$ draft and a total surface of 1.2 million square meters
(Wikipedia 2014). In the proposed simulations, Gioia Tauro is the chosen hub port. In Table 2 the distances in [nautical miles] between the North Adriatic ports and Gioia Tauro are shown.

Table 2. Distances between the North Adriatic ports and Gioia Tauro [nautical miles]

\begin{tabular}{|l|c|c|c|c|}
\cline { 2 - 5 } \multicolumn{1}{c|}{} & $\begin{array}{c}\text { Port } \\
\text { of Trieste }\end{array}$ & $\begin{array}{c}\text { Port } \\
\text { of Rijeka }\end{array}$ & $\begin{array}{c}\text { Port } \\
\text { of Venice }\end{array}$ & $\begin{array}{c}\text { Port of } \\
\text { Gioia } \\
\text { Tauro }\end{array}$ \\
\hline Port of Koper & 3 & 137 & 62 & 686 \\
\hline Port of Trieste & & 137 & 62 & 686 \\
\hline Port of Rijeka & & & 120 & 626 \\
\hline Port of Venice & & & & 667 \\
\hline
\end{tabular}

Since navigation costs are linearly well connected with travelled paths, it is reasonable to use data proposed in Table 2 as navigation costs.

THC are shipping costs related to the embarking or disembarking of a container and the costs of moving a container at the terminal. THC incorporates the next costs (Simonella et al. 2012):

- delivery metric ton and receiving full and all associated work and reporting;

- inspection and reporting the condition of the container;

- inspection and reporting of seals and wiring, removal of invalid labels, re-sealing;

- movement of the container on/off the chassis, barge or wagon;

- internal transport of the container to or from the stack;

- handling of the container into or out of the stack;

- reporting of the chassis; barge and wagon activities in and out of the terminal;

- storage of the full container within time-defined limits;

- taking the laden box out of the stack;

- internal transport from the stack to the ship's side under hook;

- move the container from ship's side to ship's rail.

THC in the North Adriatic port system are between $€ 100 / \mathrm{TEU}$ and $€$ 200/TEU (Simonella et al. 2012). It is therefore reasonable to define $\underline{T H C}=100$ and $\overline{T H C}=200$.

The collaboration indices $\gamma_{i j}$ and the relevance indices $\omega_{i}$ are difficult to express since they are the result of multiple factors, including the infrastructure of the terminal, geographical location, connections with the hinterland and both the global and local economic and political situations.

The initial values of the relevance indices are defined as a ratio between the port annual volume handled and the total NAPA system annual volume handled. The then obtained values are adjusted by technical data and expert assessment of the possibilities of development and progress of the ports. These corrections are made in accord with Eq. (18) and do not affect the initial value more than $20 \%$. Some technical data that are used to define those values are proposed in Table 3. 
Table 3. Container terminal handling facilities, shipping and rail services (MDSTL 2012)

\begin{tabular}{|l|c|c|c|c|}
\cline { 2 - 5 } \multicolumn{1}{c|}{} & Port of Koper & Port of Trieste & Port of Venice & Port of Rijeka \\
\hline Volume handled in 2010 [TEU] & 477000 & 282000 & 233000 & 137000 \\
\hline Length of quay [m] & 600 & 770 & 850 & 460 \\
\hline Max. draft alongside [m] & 11.4 & 17.4 & 10.60 & 10.50 \\
\hline Number of cranes & 8 & 7 & 6 & 4 \\
\hline Terminal area [million m ${ }^{2}$ ] & 0.30 & 0.40 & 0.5 & 0.15 \\
\hline $\begin{array}{l}\text { Capacity advertised by terminal } \\
\text { operator [million TEU] }\end{array}$ & 0.7 & 0.6 & $4 \times 400$ & 0.17 \\
\hline Rail sidings within terminal [m] & $2 \times 671 ; 1 \times 647$ & $5 \times 600$ & & $14 \times$ sidings \\
\hline
\end{tabular}

To analyse the scenarios of cooperation or competition between the North Adriatic spoke ports, a simulation will be defined which will equally use all the ports and allow neighbouring ports to compete with the other.

In the performed simulations, 2400 TEU containers will be moved from the hub port to spoke ports with a ship of capacity $2500 \mathrm{TEU}$.

The solution of the two stage optimization problem is obtained using the optimization tool IBM ILOG CPLEX Optimization Studio Version: 12.6.0.0.

The first simulation deals with the case where one shipping operator plays the role of leader and the spoke ports are followers in a situation of perfect competition.

The optimal path is formed by one cycle that connects all the ports (Fig. 1). In this case, the optimal solution is obtained by setting the THC values to minimum at $€ 100 /$ TEU.

The optimum value of the shipping operator objective function is $€ 241495$ (Eq. (1)) and the values of the spoke port objective functions are all equal to $€ 60000$ (Eq. (15)).

This solution practically is not optimal, since the ship capacity is not used rationally and the duration of the cycle is more than 10 days. Generally the Northern Adriatic ports are connected weekly by feeder ships, so their services could be competitive with those of other European ports.

In case of two ships with a capacity of 1200 TEU and two cycles, the value of the shipping operator objective function is $€ 242788$ (Eq. (1)) and the values of the

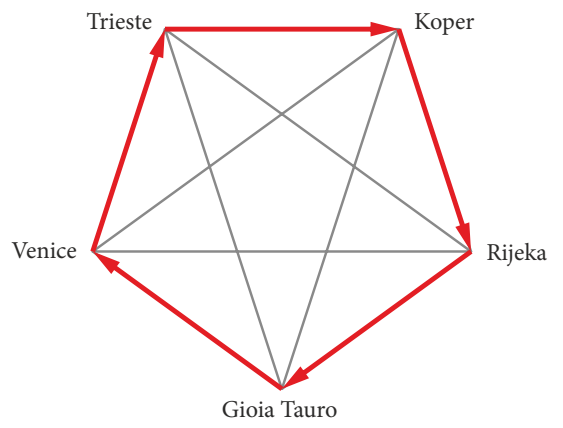

Fig. 1. Optimal path in case of one ship with a capacity of $2500 \mathrm{TEU}$ spoke port objective functions are (Eq. (15)) all equal to $€ 60000$ (Fig. 2).

The increase in the costs of the shipping company is equal to $€ 1293$; the spoke port incomes remain the same.

By changing the values of collaboration indices $\gamma_{i j}$ it is possible to highlight a competition between the ports of Koper and Trieste, since those ports cover the same hinterland.

Competition between the other ports is more complicated since they are more distant from each other and each has quite different political, economic and geographical characteristics.

In case that Koper sees an increase of $30 \%$ in the container traffic at the expense of Trieste, the values of the objective functions are the following:

- shipping operator objective function is $€ 242788$ (Eq. (1));

- spoke ports of Rijeka and Venice objective functions values are $€ 60000$ (Eq. (15));

- spoke port of Koper objective function value is $€$ 78000 (Eq. (15));

- spoke port of Trieste objective function value is $€ 42000$ (Eq. (15)).

The second simulation is the case where one shipping operator plays the role of leader and the spoke ports are followers in a situation of perfect cooperation.

In this case, the optimal solution is obtained by setting the THC values to the maximum at $€ 200 /$ TEU. The optimal solution is that proposed in Fig. 1. The value

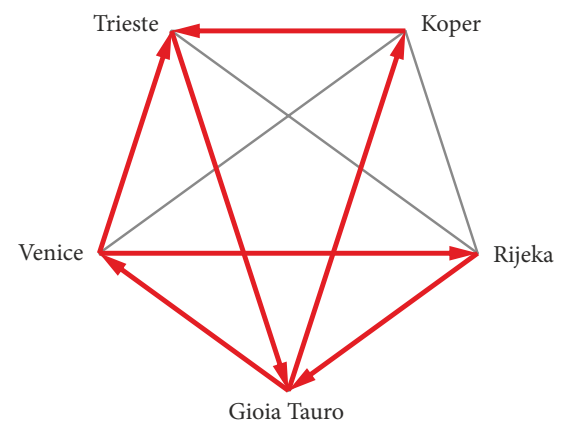

Fig. 2. Optimal paths with two ships of capacity $1200 \mathrm{TEU}$ 
of the shipping operator objective function is $€ 241495$ (Eq. (1)) and the values of the spoke ports objective functions are all equal to $€ 120000$ (Eq. (15)). As in the previous case, the same considerations about the ship operator may be applied.

The third simulation analysed cooperation among spoke ports and the shipping operator. Relevance indices $\omega_{i}$ that are used in Eq. (19) are difficult to define, since their values are a result of the economic and infrastructural characteristics of the container terminals. In this article, the data from Table 3 is used to define their values: $\omega_{1}$ the relevance index of the spoke port of Rijeka is $0.1, \omega_{2}$ the relevance index of the spoke port of Koper is $0.4, \omega_{3}$ the relevance index of the spoke port of Trieste is 0.2 and $\omega_{4}$ the relevance index of the spoke port of Venice is 0.3 .

In this case, it is impossible to find an optimal strategy since the improvement of the objective function of the ship operator causes a worsening of the objective functions of the spoke ports (Table 4). The optimal solution obtained by the simulation is not consistent with the real data.

Table 4. Objective function values

\begin{tabular}{|c|c|c|}
\hline THC & Ship operator costs & Total spoke port incomes \\
\hline 100 & 241495 & 240000 \\
\hline 110 & 265495 & 264000 \\
\hline 120 & 289495 & 288000 \\
\hline 130 & 313495 & 312000 \\
\hline 140 & 337495 & 336000 \\
\hline 150 & 361495 & 360000 \\
\hline 160 & 385495 & 384000 \\
\hline 170 & 409495 & 408000 \\
\hline 180 & 433495 & 432000 \\
\hline 190 & 457495 & 456000 \\
\hline 200 & 481495 & 480000 \\
\hline
\end{tabular}

\section{Conclusions}

The North Adriatic spoke ports system is attempting to become more competitive with respect to the other Mediterranean ports and the ports in the North of Europe. The simulations given demonstrate that cooperation between spoke ports could raise incomes and improve container transhipment services, so the efforts to improve collaboration inside the NAPA systems are correct and may increase the market share of these ports with respect to the large ports in Northern Europe.

Competition between the ports of the North Adriatic could create differences inside the system: ports with better handling facilities, shipping and rail services tend to overwhelm the others. The simulation explains that the ports of Koper and Trieste could be the main competitors in the system. Competition could lead to a reduction in the activities of the weaker port.

There is no optimal strategy in the case of cooperation between ship companies and spoke ports (Table 4), however, prudent global collaboration could be a good strategy to improve the whole system performance with respect to other European ports. In this case, it is important to establish an economically competitive balance between the needs of the ship companies and the needs of the ports. This alliance could increase the container transhipment in the hub and spoke system and bring stability to the system.

Therefore, the proposed model trough the proposed review of various scenarios of cooperation and competition in the hub and spoke system could be a starting point to the improvement of the NAPA system and to find an optimal strategy that could validate and improve business decisions of the players.

The proposed model could be also applied to other hub and spoke systems. In this case, the relevance indices, collaboration indices and navigation costs should be adapted to the new system. Another possibility of development could be the introduction of transportation and handling times in the model definition, this permits one to make the model closer to the players' needs and requirements.

\section{References}

Acciaro, M. 2013. A critical review of port pricing literature: what role for academic research?, The Asian Journal of Shipping and Logistics 29(2): 207-228.

http://doi.org/10.1016/j.ajsl.2013.08.005

Asgari, N.; Farahani, R. Z.; Goh, M. 2013. Network design approach for hub ports-shipping companies competition and cooperation, Transportation Research Part A: Policy and Practice 48: 1-18. http://doi.org/10.1016/j.tra.2012.10.020

Chang, Y.-T.; Lee, S.-Y.; Tongzon, J. L. 2008. Port selection factors by shipping lines: different perspectives between trunk liners and feeder service providers, Marine Policy 32(6): 877-885. http://doi.org/10.1016/j.marpol.2008.01.003

Chen, C.; Zeng, Q.; Zhang, Z. 2012. An integrating scheduling model for mixed cross-operation in container terminals, Transport 27(4): 405-413. http://doi.org/10.3846/16484142.2012.753642

Chong, E. K. P.; Zak, S. H. 2013. An Introduction to Optimization. 4th edition. Wiley. 640 p.

Colson, B.; Marcotte, P.; Savard, G. 2007. An overview of bilevel optimization, Annals of Operations Research 153(1): 235-256. http://doi.org/10.1007/s10479-007-0176-2

Dempe, S. 2002. Foundations of Bilevel Programming. Springer. 309 p. http://doi.org/10.1007/b101970

Imai, A.; Shintani, K.; Papadimitriou, S. 2009. Multi-port vs. hub-and-spoke port calls by containerships, Transportation Research Part E: Logistics and Transportation Review 45(5): 740-757. http://doi.org/10.1016/j.tre.2009.01.002

Ishii, M.; Lee, P. T.-W.; Tezuka, K.; Chang, Y.-T. 2013. A game theoretical analysis of port competition, Transportation Research Part E: Logistics and Transportation Review 49(1): 92-106. http://doi.org/10.1016/j.tre.2012.07.007

Liu, Q.; Medda, F. 2009. Port infrastructure efficiency: the Europe-Mediterranean case, International Journal of Shipping and Transport Logistics 1(4): 361-385. http://doi.org/10.1504/IJSTL.2009.027680

Marler, R. T.; Arora, J. S. 2004. Survey of multi-objective optimization methods for engineering, Structural and Multidisciplinary Optimization 26(6): 369-395. http://doi.org/10.1007/s00158-003-0368-6 
MDSTL. 2012. NAPA: Market Study on the Potential Cargo Capacity of the North Adriatic Ports System in the Container Sector. Final Report 211015R3. 78 p. MDS Transmodal Limited (MDSTL). Available from Internet: http:// www.assoporti.it/sites/www.assoporti.it/files/documenti/ MDS-\%20NAPA\%20cntrs\%20market\%20-\%20final\%20 report.pdf

Meng, Q.; Wang, X. 2011. Intermodal hub-and-spoke network design: Incorporating multiple stakeholders and multi-type containers, Transportation Research Part B: Methodological 45(4): 724-742. http://doi.org/10.1016/j.trb.2010.11.002

NAPA. 2013. North Adriatic Ports Association (NAPA). Available from Internet: http://www.portsofnapa.com

Nie, P.-Y. 2011. Dynamic discrete-time multi-leader-follower games with leaders in turn, Computers \& Mathematics with Applications 61(8): 2039-2043.

http://doi.org/10.1016/j.camwa.2010.08.063

Panayides, P. M.; Wiedmer, R. 2011. Strategic alliances in container liner shipping, Research in Transportation Economics 32(1): 25-38. http://doi.org/10.1016/j.retrec.2011.06.008

Rasmusen, E. 2006. Games and Information: an Introduction to Game Theory. 4th edition. Wiley-Blackwell. 558 p.

Saeed, N.; Larsen, O. I. 2013. A tale of two ports: extending the Bertrand model along the needs of a case study, in H. Hanappi (Ed.). Game Theory Relaunched, 77-104. http://doi.org/10.5772/54425

Saeed, N.; Larsen, O. I. 2010a. An application of cooperative game among container terminals of one port, European Journal of Operational Research 203(2): 393-403. http://doi.org/10.1016/j.ejor.2009.07.019

Saeed, N.; Larsen, O. I. 2010b. Container terminal concessions: a game theory application to the case of the ports of Pakistan, Maritime Economics \& Logistics 12(3): 237-262. http://doi.org/10.1057/mel.2010.8

Simonella, I.; Pettenati, P.; Balloni, V. 2012. Intermodalità: dalle infrastrutture allo sviluppo dei servizi. Rapporto 2012. Istituto Adriano Olivetti, Italy. 70 p. (in Italian).

Song, D.-P.; Dong, J.-X. 2012. Cargo routing and empty container repositioning in multiple shipping service routes, Transportation Research Part B: Methodological 46(10): 1556-1575. http://doi.org/10.1016/j.trb.2012.08.003

Toth, P.; Vigo, D. 2014. Vehicle Routing: Problems, Methods, and Applications. 2nd edition. Society for Industrial and Applied Mathematics (SIAM). 481 p.

Turocy, T. L.; Stengel, B. V. 2003. Game theory, in H. Bidgoli (Ed.). Encyclopedia of Information Systems, 403-420. http://doi.org/10.1016/B0-12-227240-4/00076-9

Wang, C.; Wang, J. 2011. Spatial pattern of the global shipping network and its hub-and-spoke system, Research in Transportation Economics 32(1): 54-63. http://doi.org/10.1016/j.retrec.2011.06.010

Wikipedia. 2014. Port of Gioia Tauro. Available from Internet: http://en.wikipedia.org/wiki/Port_of_Gioia_Tauro 